\title{
Tendencies toward Internet-pornography-use disorder: Differences in men and women regarding attentional biases to pornographic stimuli
}

\author{
JARO PEKAL ${ }^{1}$, CHRISTIAN LAIER $^{1}$, JAN SNAGOWSKI $^{1}$, RUDOLF STARK $^{2,3}$ and MATTHIAS BRAND ${ }^{1,4 *}$ \\ ${ }^{1}$ Department of General Psychology: Cognition and Center for Behavioral Addiction Research (CeBAR), \\ University of Duisburg-Essen, Duisburg, Germany \\ ${ }^{2}$ Department of Psychology and Systems Neuroscience, Justus Liebig University Giessen, Giessen, Germany \\ ${ }^{3}$ Bender Institute of Neuroimaging, Justus Liebig University Giessen, Giessen, Germany \\ ${ }^{4}$ Erwin L. Hahn Institute for Magnetic Resonance Imaging, Essen, Germany
}

(Received: January 8, 2018; revised manuscript received: June 10, 2018; accepted: June 11, 2018)

\begin{abstract}
Background and aims: Several authors consider Internet-pornography-use disorder (IPD) as addictive disorder. One of the mechanisms that has been intensively studied in substance- and non-substance-use disorders is an enhanced attentional bias toward addiction-related cues. Attentional biases are described as cognitive processes of individual's perception affected by the addiction-related cues caused by the conditioned incentive salience of the cue itself. It is assumed in the I-PACE model that in individuals prone to develop IPD symptoms implicit cognitions as well as cuereactivity and craving arise and increase within the addiction process. Methods: To investigate the role of attentional biases in the development of IPD, we investigated a sample of 174 male and female participants. Attentional bias was measured with the Visual Probe Task, in which participants had to react on arrows appearing after pornographic or neutral pictures. In addition, participants had to indicate their sexual arousal induced by pornographic pictures. Furthermore, tendencies toward IPD were measured using the short-Internetsex Addiction Test. Results: The results of this study showed a relationship between attentional bias and symptom severity of IPD partially mediated by indicators for cue-reactivity and craving. While men and women generally differ in reaction times due to pornographic pictures, a moderated regression analysis revealed that attentional biases occur independently of sex in the context of IPD symptoms. Discussion: The results support theoretical assumptions of the I-PACE model regarding the incentive salience of addiction-related cues and are consistent with studies addressing cue-reactivity and craving in substance-use disorders.
\end{abstract}

Keywords: Internet-pornography-use disorder, attentional bias, addiction

\section{INTRODUCTION}

Since the Internet has become an important tool to cope with several goals or to fulfill certain needs, it is evident that many individuals use it also for sexual purposes (Döring, 2009). The majority of Internet pornography users experience positive effects, such as an enrichment of individual's sex life or inspiration of sexual imagination (Grov, Gillespie, Royce, \& Lever, 2011; Hald \& Malamuth, 2008; Paul, 2009; Shaughnessy, Byers, Clowater, \& Kalinowski, 2014). Some users, however, seem to develop an excessive usage pattern characterized by increased using times as well as a diminished control over the use and they experience severe negative consequences due to their uncontrolled use of Internet pornography (Griffiths, 2012). Due to the easy accessibility and affordability of pornographic contents as well as users' perceived anonymity (Cooper, 1998), the Internet-pornography-use seems to be risky for its addictive potential (Griffiths, 2001; Meerkerk, van den Eijnden, \& Garretsen, 2006; Young, Pistner, O’Mara, \& Buchanan, 1999). With regard to several other Internet applications (e.g., social networking or shopping), it is discussed whether or not the phenomenon of an uncontrolled and excessive use of Internet pornography might be considered as one type of specific Internet-use disorder (Brand, Young, Laier, Wölfling, \& Potenza, 2016; Garcia \& Thibaut, 2010; Kuss, Griffiths, Karila, \& Billieux, 2014; Laier \& Brand, 2014). Although discussed controversially, several authors consider Internet-pornography-use disorder (IPD) as an addictive disorder, which is comparable with Internet gaming disorder or gambling disorder. Consequently, applying the addiction framework is useful for studying psychological mechanisms potentially underlying IPD. One of the mechanisms that has been intensively studied in substance-use disorders is an enhanced attentional bias toward addiction-related cues (Bradley, Mogg, Wright, \& Field, 2003; Field, Marhe, \&

\footnotetext{
* Corresponding author: Matthias Brand; Department of General Psychology: Cognition and Center for Behavioral Addiction Research (CeBAR), University of Duisburg-Essen, Forsthausweg 2, 47057 Duisburg, Germany; Phone: +49 203379 2541; Fax: +49 203379 1846; E-mail: jaroslaw.pekal@uni-due.de
}

This is an open-access article distributed under the terms of the Creative Commons Attribution-NonCommercial 4.0 International License, which permits unrestricted use, distribution, and reproduction in any medium for non-commercial purposes, provided the original author and source are credited, a link to the CC License is provided, and changes - if any - are indicated. 
Franken, 2014; van Hemel-Ruiter, de Jong, Ostafin, \& Wiers, 2015).

Attentional biases are described as cognitive processes of individual's perception affected by addiction-related cues (Field \& Cox, 2008). The theoretical background of the attentional bias hypotheses is, for example, the incentive sensitization theory by Robinson and Berridge (1993). Robinson and Berridge (1993) argue that individuals with addictive disorders show fast shifts of attention to stimuli, which are associated with the addictive behavior (e.g., drug intake), due to the cue's incentive salience. The incentive salience is considered as the result of classical conditioning processes (Robinson \& Berridge, 2000, 2001, 2008). In the context of the development and maintenance of an IPD, these attentional biases may interfere with decision-making behaviors in order to receive short-term gratification in terms of sexual arousal. It is assumed that the anticipation of sexual gratification plays a key role in the development and maintenance of an IPD as the gratification is highly positively (and partly negatively) reinforcing (Brand et al., 2011; Georgiadis \& Kringelbach, 2012; Young, 1998). Findings from previous research have shown the conditionability of sexual arousal and its reinforcing potential (Hoffmann, Janssen, \& Turner, 2004; Klucken et al., 2009) and therefore indicate the role of sexual arousal as predictor for IPD (Laier \& Brand, 2014; Snagowski, Laier, Duka, \& Brand, 2016). Attentional bias toward stimuli that are associated with the addictive behavior has already been demonstrated for Internet-gaming disorder (Dong, Zhou, \& Zhao, 2011; Jeromin, Nyenhuis, \& Barke, 2016; Lorenz et al., 2012; Metcalf \& Pammer, 2011) but not for IPD, to date.

In the recently published theoretical framework, the Interaction of Person-Affect-Cognition-Execution (I-PACE) model (Brand et al., 2016) of specific Internet-use disorders, the authors assume interactions between subjectively perceived situational triggers and cognitive responses to specific cues. This assumption is based on the dual-process theory (Bechara, 2005), whereby an addictive behavior can be seen as a result of an interaction between an automatic, impulsive and a more controlled reflective processing. Considering cognitive and affective responses to specific cues in the addiction process, attentional biases result from an imbalance between these two processes and are more impulsive rather than rationally driven as they are a consequence of cue-reactivity (Bechara, 2005). A repeated confrontation with addiction-related cues within the addiction's development process strengthens attentional biases and therefore increases craving responses to those cues. Research on hypersexual behaviors could show that addicted individuals react faster on sexual stimuli in terms of an enhanced attentional bias compared to healthy individuals (Mechelmans et al., 2014). The I-PACE model hypothesizes that in individuals prone to develop IPD symptoms implicit cognitions, such as attentional bias, as well as cue-reactivity and craving arise and increase within the addiction process. While craving is mostly referred to a subjectively experienced need to consume a drug (Sayette et al., 2000), cue-reactivity represents subjective and physiological responses to addiction-related cues (Drummond, 2001) and is therefore a more conscious response than an implicit attentional bias. Thus, we assume that the effect of attentional biases on IPD symptoms is mediated by cue-reactivity and craving.

Contrary to the general perception, pornography is not exclusively consumed by men, but receives growing attention by female users, even if the time of usage and choice of content differ from males' consumption (Daneback, Cooper, \& Månsson, 2005; Ferree, 2003; Shaughnessy, Byers, \& Walsh, 2011). Despite the limited number of studies on addictive behaviors in female users, there is an empirical evidence for similarities between male and female users (Green, Carnes, Carnes, \& Weinmann, 2012; Laier, Pekal, $\&$ Brand, 2014). The results for men and women are consistent with the previous findings, suggesting that sexual arousal and craving are main predictors for the development and maintenance of an IPD and are based on learned associations to internal and external cues (Brand et al., 2011; Laier, Pawlikowski, Pekal, Schulte, \& Brand, 2013). In addition, research suggests that attentional bias toward sexual stimuli can occur independently of sex. Kagerer et al. (2014) could show that male and female participants did not differ in reaction times in terms of attentional bias toward sexual cues. However, it is still unclear how an attentional bias interacts with symptoms of an IPD. Due to the theoretical assumptions of the I-PACE model (Brand et al., 2016) and first empirical evidence on the appearance of attentional biases toward sexual stimuli in male and female participants (Kagerer et al., 2014), we hypothesize:

H1: Attentional biases toward pornographic pictures are associated with higher symptom severity of IPD.

$H 2$ : There is a relationship between attentional bias and indicators for cue-reactivity and craving.

H3: The relationship between attentional bias and symptoms of IPD is independent from gender.

H4: The effect of attentional bias on symptoms of IPD is mediated by indicators for craving and cuereactivity.

\section{METHODS}

\section{Participants}

We examined 174 participants $\left(n=87\right.$ females, $M_{\text {age }}=23.59$, $S D=4.93$ years, range: $18-52$ years) for this study. All participants were recruited trough offline and online advertisements at the University Duisburg-Essen. Advertisements explicitly asked for participants of full-age and informed about the confrontation with pornographic pictures of legal content during examination. All participants gave written informed consent prior to the investigation. The study was approved by the local ethics committee. Investigation took place in a laboratory setting. Students were able to collect course credits and non-students were paid at an hourly rate of $10 €$. The sample's mean time spent on pornographic websites was $M_{\text {total }}=70.82(S D=280.21)$ min per week. While male participants reported to spend $121.71 \mathrm{~min}(S D=$ 387.51 ) per week on pornographic websites, women reported a weekly pornography use of $19.92 \mathrm{~min}(S D=50.44)$ on average. 


\section{Visual Probe Task}

The Visual Probe Task (Bradley, Field, Healy, \& Mogg, 2008) was used to assess attentional bias. For the context of Internet pornography, the paradigm was modified with 16 pornographic pictures out of four categories (male/female oral sex and vaginal intercourse; female/female oral sex and vaginal intercourse). To provide an adequate neutral counterpart of the pornographic cues, a mostly enlarged cutout from each pornographic picture was excluded free of any sexually representation matched for color and color intensity (Figure 1). That matching was consciously chosen to ensure the same color intensity attention level for neutral and pornographic cues and to constrain the differential only to a sexual component. These 16 neutral cues were similar in terms of color, but neither with any explicit sexual details nor with a recognition value of the actors. Each pornographic picture was presented simultaneously to its neutral counterpart (Figure 2). There were two conditions: cues were presented for either 2000 or $200 \mathrm{~ms}$. Following the presentation of a pair of pornographic-neutral pictures, a small arrow (probe) occurred pointing in an upper or lower direction. This arrow occurred at the position of either a pornographic or a neutral cue until participant's response. Participants had to indicate the direction of arrow as fast and correct as possible by pushing one of two buttons on a keyboard. The position of each cue varied trial-by-trial between left and right resulting in a total number of 256 randomized trials [16 pairs (pornographic/neutral), 2 conditions $(200 / 2000 \mathrm{~ms}), 2$ positions of cue (left/right), 2 positions of arrow (left/right), and 2 directions of arrow (up/down)]. Participants completed a practice trial before beginning the experimental trials. There was a short break after 128 trials. The basic idea of the Visual Probe Task is the presentation of addiction-related and neutral cues followed by the measurement of reaction times by subtracting wrong reactions on arrows. The main scores were calculated by subtracting the reaction times for the arrow appearing after the pornographic picture from reaction times for the arrow appearing after the neutral pictures. A positive score represents faster reaction times for arrows appearing after a pornographic picture and therefore an attentional bias.

Pornographic picture (uncensored in study)

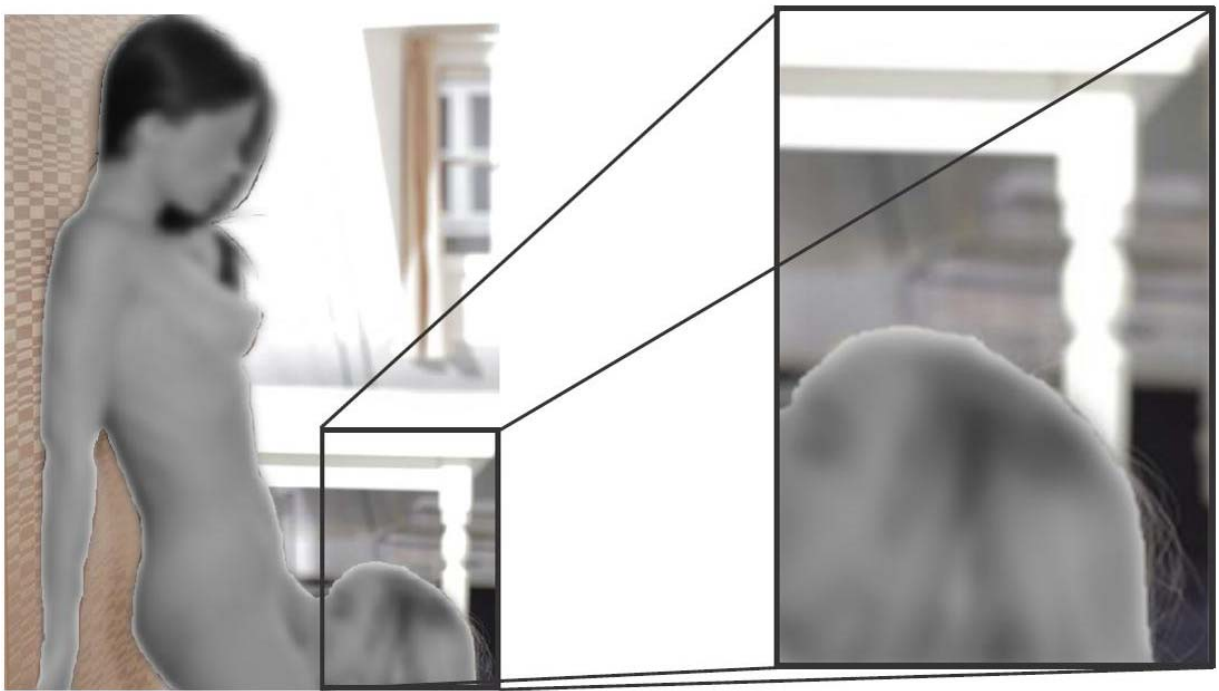

Figure 1. Example for a pornographic and neutral cue used in the Visual Probe Task. The neutral cue was a cutout from a pornographic picture matched for color and color intensity and free of any sexually details. The pornographic pictures were presented uncensored in the study

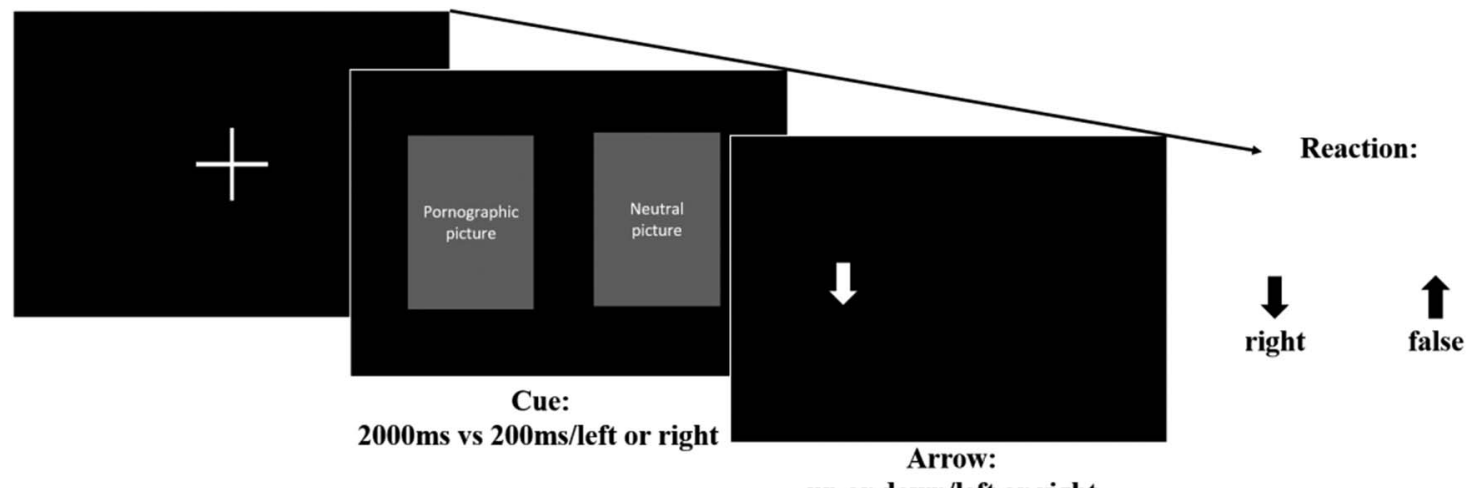

up or down/left or right

Figure 2. Representation of sequence for the Visual Probe Task. Participants had to react on an arrow pointing up or down, which appeared either after a pornographic or neutral picture 
The scores were an initial attentional bias for the $200 \mathrm{~ms}$ condition (initial AB), a maintained score for the $2000 \mathrm{~ms}$ condition (maintained $\mathrm{AB}$ ), and an overall score (overall $A B$ ), which is a mean score of the initial and the maintained AB. Higher scores indicate a higher attentional bias to pornographic picture cues.

\section{Internet-pornography-use disorder}

To assess the severity of complaints and negative consequences in everyday life due to Internet-pornography-use, a German version of the short-Internet Addiction Test (Pawlikowski, Altstötter-Gleich, \& Brand, 2013) was used, which was modified for Internetsex sites [short-Internetsex Addiction Test (s-IATsex); Laier et al., 2013]. This questionnaire consists of 12 items, of which each item has to be rated on a scale ranging from $1=$ "never" to $5=$ "very often" resulting in an overall score ranging from 12 to 60 . The s-IATsex has a two-dimensional structure consisting of the subscale s-IATsex-control measuring a loss of control and difficulties in time management and s-IATsex-craving measuring symptoms of craving and social problems (six items). One example for an item would be "How often do you try to cut down the amount of time you spend on Internetsex sites and fail?" In this sample, the s-IATsex had a good internal consistency of Cronbach's $\alpha=.893$ for the overall score, Cronbach's $\alpha=.878$ for s-IATsex-control, and Cronbach's $\alpha=.764$ for s-IATsex-craving.

\section{Sexual arousal and craving}

To induce sexual arousal and craving, participants were presented 100 pornographic pictures out of 10 categories (male/female oral, vaginal, and anal intercourse; male/male oral and anal intercourse; female/female oral and vaginal intercourse; and male and female masturbating). This paradigm was used in several studies earlier (Laier et al., 2013, 2014; Laier, Pekal, \& Brand, 2015). Each picture had to be rated with respect to sexual arousal and attractiveness on a scale ranging from $1=$ "not sexual arousal at all"/"not attractive at all" to 5= "very sexual arousal"/"very attractive." Mean scores were calculated only for pictures, which are seen to be arousing for heterosexual individuals (male/female oral, vaginal, and anal intercourse and female/female oral and vaginal intercourse) (pictures arousal and pictures attractiveness). Before ( $t 1)$ and after (t2) the picture presentation, the participants had to indicate their current sexual arousal and their need to masturbate on a scale ranging from 1 to 100 . The increase of sexual arousal (arousal $\Delta$ ) and the increase of the need to masturbate (craving masturbation $\Delta$ ) were assumed as the indicators for cue-reactivity and craving responses and were calculated by subtracting $\mathrm{t} 2$ from $\mathrm{t} 1$. Time point $\mathrm{t} 1$ is considered as baseline measure. The pornographic pictures were presented prior to the Visual Probe Task.

\section{Statistical analysis}

For moderated regression analysis, all independent variables were centralized (Cohen, Cohen, West, \& Aiken, 2003). The structural equation model on latent level was calculated using Mplus 6 (Muthén \& Muthén, 2011). The data set was free of missing data. We evaluated the model fit on the basis of the standard criteria: standardized root mean square residual (SRMR; values $<0.08$ indicate a good fit with the data), comparative fit index/Tucker-Lewis index (CFI/TLI; values $>0.90$ indicate an acceptable and $>0.95$ a good fit with the data), and root mean square error of approximation (RMSEA; values $<0.08$ indicate a good and 0.08-0.10 an acceptable model fit) (Hu \& Bentler, 1995, 1999). The $\chi^{2}$-test was used to check if the data derivated from the defined model. All relevant variables for the mediation were required to correlate with each other (Baron \& Kenny, 1986).

\section{Ethics}

All participants were fully instructed and gave written consent prior to the investigation. The study was approved by the local ethics committee.

\section{RESULTS}

Descriptive values of all variables are summarized in Table 1. Male participants showed a mean score for the s-IATsex of $18.85(S D=6.22$, range: $12-42)$, whereas female participants had a mean score of 14.34 ( $S D=$ 4.35, range: 12-37). Based on cut-off scores for the short-Internet Addiction Test (s-IAT; original questionnaire for symptoms of an Internet-use disorder) (Pawlikowski et al., 2013), this sample consists of two problematic and pathological female users $(2.2 \%)$ and eight problematic and pathological male users $(8.9 \%)$. A $t$-test for independent samples showed significant differences between male and female participants regarding symptoms of an IPD (s-IATsex), attentional biases (maintained and overall), and picture ratings (sexual arousal and attractiveness). No differences were found for indicators of craving (arousal and need to masturbate) and the 200-ms attentional bias condition (initial AB) (Table 1). Correlations between tendencies toward IPD, indicators for sexual arousal and craving, and measures for attentional biases are shown in Table 2. As hypothesized, the results indicate relationships between attentional bias, symptoms of IPD, and indicators for cue-reactivity and craving.

Two moderated hierarchical regression analyses were conducted to explore potential interactions between the group variable "sex" and measures of attentional biases on tendencies toward IPD. Moreover, a post hoc power analysis for determining the effect sizes as well as the sample size's power for both regression analyses was calculated. As dependent variable, the subscale "s-IATsex-craving" was chosen, as it is assumed that attentional bias has effects on symptoms of craving and that this subscale assesses subjective complaints of craving more specifically than the "s-IATsex sum score" does. The group variable "sex" was the predictor and the "initial AB score" was used as moderator variable. In the first step, the group variable "sex" showed a significant explanation of variance in the dependent variable "s-IATsex-craving" of $9.9 \% \quad(F=$ $18.970, p<.001)$. Adding the "initial AB score" in the second step significantly increases the explanation of 
Table 1. $t$-test for independent samples comparing male and female participants regarding measurements for tendencies toward IPD, sexual arousal, craving, and attentional biases

\begin{tabular}{|c|c|c|c|c|c|c|c|c|c|}
\hline & \multicolumn{2}{|c|}{ Overall $(N=174)$} & \multicolumn{2}{|c|}{ Male $(n=87)$} & \multicolumn{2}{|c|}{ Female $(n=87)$} & \multirow[b]{2}{*}{$t$} & \multirow[b]{2}{*}{$p$} & \multirow[b]{2}{*}{$d$} \\
\hline & $M$ & $S D$ & $M$ & $S D$ & $M$ & $S D$ & & & \\
\hline \multicolumn{10}{|l|}{ Symptom severity of IPD } \\
\hline s-IATsex & 16.60 & 5.81 & 18.85 & 6.22 & 14.34 & 4.35 & 5.53 & $<.001$ & 0.84 \\
\hline s-IATsex-craving & 8.13 & 2.83 & 9.02 & 2.96 & 7.24 & 2.41 & 4.36 & $<.001$ & 0.66 \\
\hline s-IATsex-control & 8.47 & 3.47 & 9.83 & 3.92 & 7.10 & 2.26 & 5.62 & $<.001$ & 0.71 \\
\hline \multicolumn{10}{|l|}{ Attentional bias scores } \\
\hline Initial $\mathrm{AB}$ & 24.99 & 30.28 & 27.93 & 32.67 & 22.06 & 27.56 & 1.28 & .202 & 0.20 \\
\hline Maintained AB & 9.41 & 29.46 & 14.23 & 28.47 & 4.60 & 29.81 & 2.18 & .031 & 0.33 \\
\hline Overall AB & 17.48 & 23.46 & 21.40 & 23.12 & 13.56 & 23.27 & 2.23 & .027 & 0.34 \\
\hline \multicolumn{10}{|l|}{ Picture presentation ratings } \\
\hline Pictures_arousal & 2.50 & 0.91 & 2.92 & 0.82 & 2.08 & 0.79 & 6.84 & $<.001$ & 1.04 \\
\hline Pictures_attractiveness & 2.55 & 0.83 & 2.92 & 0.77 & 2.18 & 0.72 & 6.56 & $<.001$ & 0.99 \\
\hline \multicolumn{10}{|l|}{ Cue-reactivity and craving } \\
\hline Arousal $\mathrm{t} 1$ & 8.22 & 15.92 & 9.61 & 18.22 & 6.84 & 13.19 & 1.15 & .252 & 0.17 \\
\hline Arousal $\mathrm{t} 2$ & 22.92 & 21.38 & 24.48 & 21.79 & 21.36 & 20.97 & 0.96 & .336 & 0.17 \\
\hline Arousal $\Delta$ & 14.70 & 18.45 & 14.48 & 19.17 & 14.52 & 17.81 & 0.13 & .899 & 0.00 \\
\hline Craving_masturbation t1 & 4.95 & 12.58 & 6.60 & 15.81 & 3.31 & 7.94 & 1.73 & .085 & 0.26 \\
\hline Craving_masturbation $\mathrm{t} 2$ & 13.44 & 18.50 & 15.08 & 19.23 & 11.79 & 17.69 & 1.17 & .242 & 0.18 \\
\hline $\begin{array}{l}\text { Craving_masturbation } \Delta \\
\text { Other }\end{array}$ & 8.48 & 14.38 & 8.48 & 13.67 & 8.48 & 15.14 & 0.00 & 1.000 & 0.00 \\
\hline Weekly porn usage (min) & 70.82 & 280.21 & 121.71 & 387.51 & 19.92 & 50.44 & 2.43 & .016 & 0.37 \\
\hline
\end{tabular}

Note. IPD: Internet-pornography-use disorder; SD: standard deviation; s-IATsex: short-Internetsex Addiction Test.

variance of "s-IATsex-craving" $\left(\Delta R^{2}=.020, \Delta F=3.968\right.$, $p=.048)$. No significant interaction effect was observed $\left(\Delta R^{2}=.00, \Delta F=0.027, p=.871\right)$. However, the regression model remained significant with an overall explanation of variance of $12 \%$ in the tendencies toward IPD $\left(R^{2}=.120\right.$, $F=7.720, p<.001)$. Further regression values are shown in Table 3. The moderated regression analysis shows a medium effect size with $f^{2}=0.14$ and a necessary power of 0.83 (1- $\beta$ err prob) (Cohen, 1992). The simple slopes (Figure 3 ) of the regression representing "low initial AB" and "high initial AB" were not significantly different from zero $\left(t_{\text {lowinitial } \mathrm{AB}}=0.13, p=.895 ; t_{\text {highinitialA }}=0.14, p=.886\right)$. In a second moderated regression analysis, the "maintained AB" was used as moderator variable (group variable and dependent variable are the same as above). Consequently, the group variable "sex" showed the aforementioned significant effect on the tendencies toward IPD (s-IATsex-craving) with $R^{2}=.099(F=18.970, p<.001)$. The maintained AB as a second predictor in this model showed a significant explanation of variance with $\Delta R^{2}=.034 \quad(\Delta F=6.660$, $p=.011)$. No significant interaction effect was found $\left(\Delta R^{2}=.002, \Delta F=0.356, p=.552\right)$. Further regression values are shown in Table 4 . The moderated regression analysis shows a medium effect size with $f^{2}=0.16$ and a necessary power of 0.89 (Cohen, 1992). Thus, the effect sizes and the power indicate that we do not mistakenly expect and accept null interactions. The simple slopes (Figure 4) of the regression representing "low maintained $\mathrm{AB}$ " and "high maintained $\mathrm{AB}$ " were not significantly different from zero $\left(t_{\text {low-maintainedAB }}=0.14, p=.893\right.$; $\left.t_{\text {high-maintainedAB }}=0.14, p=.892\right)$. Both regression and simple slope analyses indicate that individuals with higher attentional bias toward sexual stimuli report stronger symptoms of craving in the context of IPD. Therefore, the results indicate the important role of attentional bias in both sexes, because the two attentional bias scores had their own incremental validity beyond the group variable biological sex and no interaction effects between group (male and female) and attentional biases were observed.

For the mediation model, the latent variable "cuereactivity and craving" was modeled by the craving measures sexual arousal $t 2$, and the need to masturbate $t 2$ since the delta scores for both measures were not significantly correlated with the severity of symptoms due to an IPD and attentional bias scores. The assumption is that individuals with a higher symptom severity already have a higher baseline craving before watching the pornographic picture presentation. Thus, the increase of sexual arousal is small, but sexual arousal remains higher for $\mathrm{t} 2$ measure in individuals with tendencies toward an IPD. The proposed structural equation model on latent level with IPD symptoms (s-IATsex) as dependent variable showed a good fit with the underlying data. The RMSEA was $0.067(p=.279)$, CFI was 0.985 , TLI was 0.962 , and the SRMR was 0.028 . The $\chi^{2}$ test was not significant with $10.72(p=.097)$ and $\chi^{2} / d f$ was 1.79. Overall, the proposed model explained $24.1 \%$ of the variance in the IPD symptoms $\left(R^{2}=.241, p=.015\right)$. The latent mediation model with the $\beta$ weights are shown in Figure 5 . The latent variable "attentional bias" modeled by the initial $\mathrm{AB}$ and maintained $\mathrm{AB}$ had a direct effect on symptoms of IPD, which was modeled by the two subscales (s-IATsex-control and s-IATsex-craving) of the s-IATsex $(\beta=.310, S E=0.154, p=.044)$. Furthermore, attentional bias showed a direct effect on the latent variable "cue-reactivity and craving," which was represented by the subjective sexual arousal and the need to masturbate after 
Attentional biases in IPD

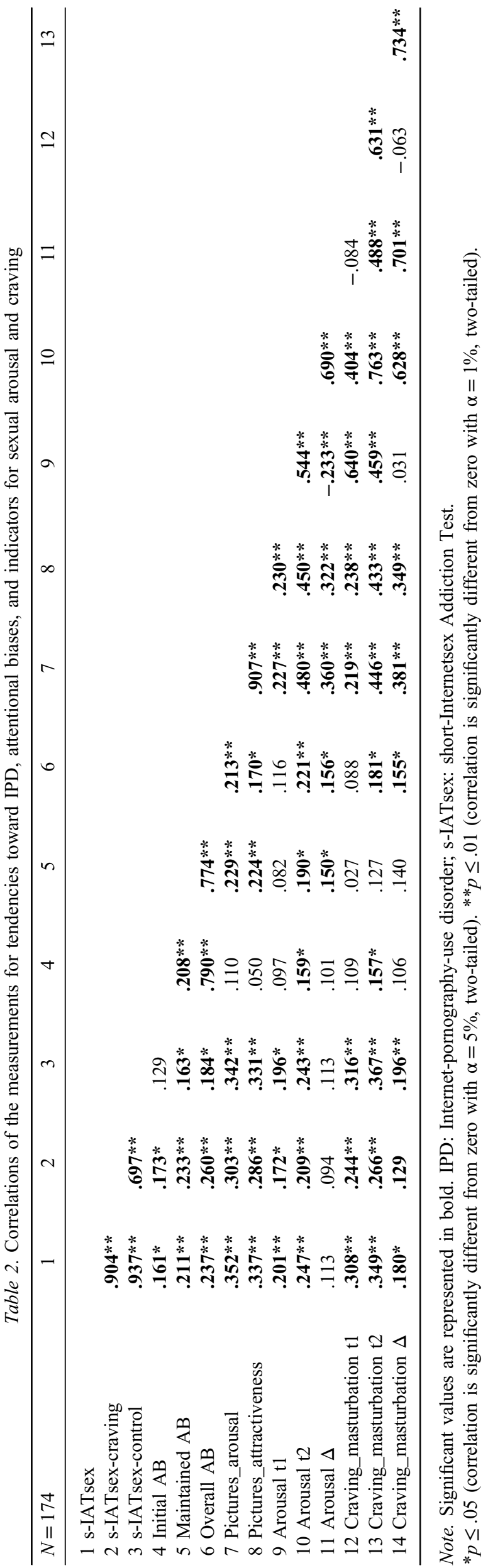

Table 3. First moderated regression analysis with s-IATsex-craving as dependent variable

\begin{tabular}{lccr}
\hline Main effects & $\beta$ & $T$ & $p$ \\
\hline Sex & .301 & 4.17 & $<.001$ \\
Initial AB & .142 & 1.93 & .055 \\
Sex $\times$ Initial AB & .012 & 0.16 & .871 \\
\hline
\end{tabular}

Note. Significant value is represented in bold. s-IATsex: shortInternetsex Addiction Test.

Table 4. Second moderated regression analysis with s-IATsexcraving as dependent variable

\begin{tabular}{lccr}
\hline Main effects & $\beta$ & $T$ & \multicolumn{1}{c}{$p$} \\
\hline Sex & .285 & 3.94 & $<. \mathbf{0 0 1}$ \\
Maintained AB & .184 & 2.55 & $\mathbf{. 0 1 2}$ \\
Sex $\times$ Maintained AB & -.043 & -0.60 & .552 \\
\hline
\end{tabular}

Note. Significant value is represented in bold. s-IATsex: shortInternetsex Addiction Test.

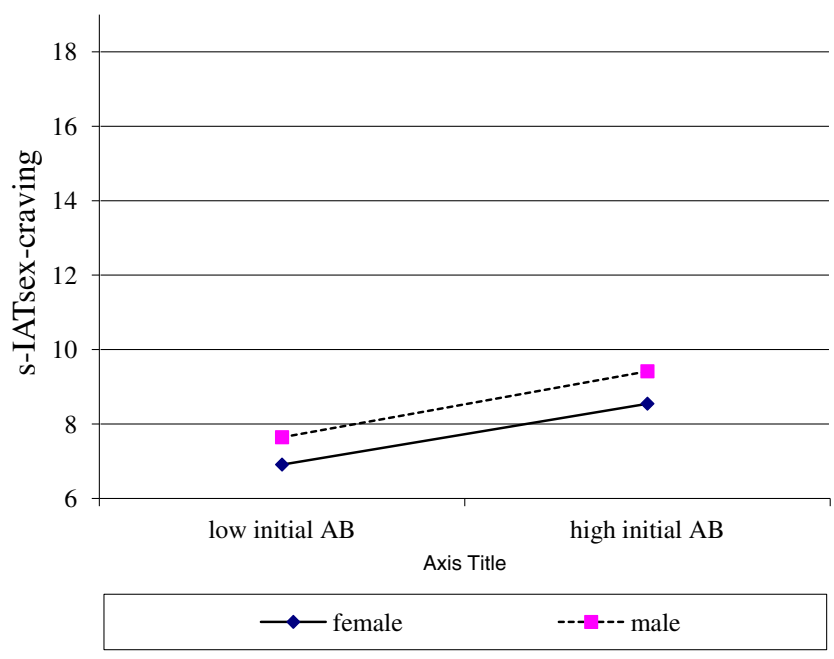

Figure 3. Simple slopes for the first moderated regression analysis with s-IATsex-craving as dependent variable, the first moderated regression analysis with s-IATsex-craving as dependent variable, sex as independent variable, and initial $\mathrm{AB}$ as moderator. No interaction was found and simple slopes did not differ significantly from zero

watching pornographic pictures $(\beta=.297, S E=0.145$, $p=.041)$. In addition, there was a direct effect from cuereactivity and craving on symptoms of IPD $(\beta=.299, S E=$ $0.093, p<.001)$. Overall, attentional bias showed an indirect effect on IPD symptoms $(\beta=.089, S E=0.045$, $p=.047)$ indicating a partially mediation over indicators for cue-reactivity and craving.

\section{DISCUSSION}

As a main result of the study, we found the hypothesized relationship between attentional bias toward sexual stimuli and symptom severity of IPD in a sample of male and female participants. Furthermore, the relationship between attentional bias and symptoms of IPD was mediated by indicators for cue-reactivity and craving. The results indicate a difference between male and female individuals 


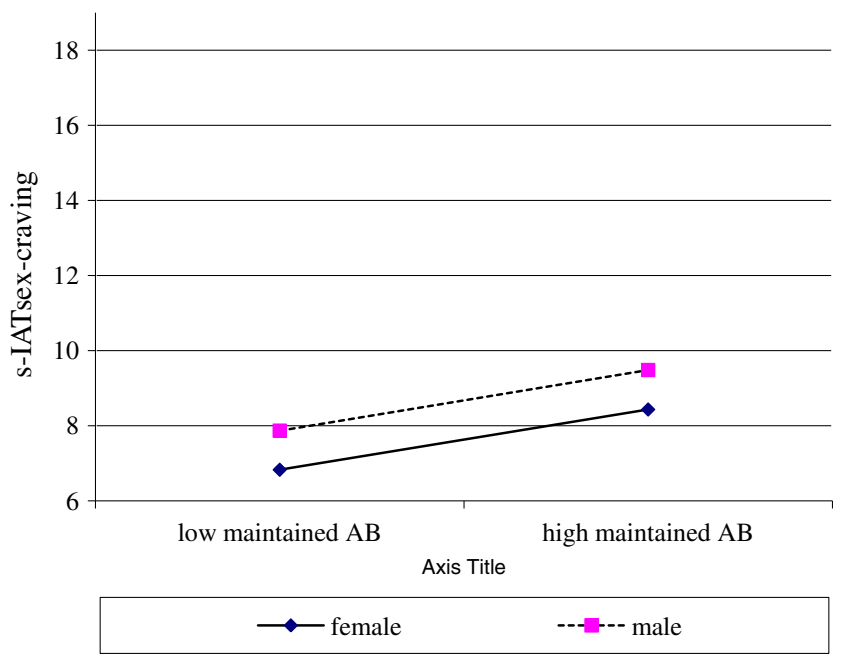

Figure 4. Simple slopes for the second moderated regression analysis with s-IATsex-craving as dependent variable, the first moderated regression analysis with s-IATsex-craving as dependent variable, sex as independent variable, and maintained $\mathrm{AB}$ as moderator. No interaction was found and simple slopes did not differ significantly from zero

regarding an attentional bias for the overall and maintained condition, but not in the initial condition in the Visual Probe Task. However, regression analysis could show that sex and attentional biases in both time conditions predicted tendencies toward IPD, the interaction of both did not add further explanation of variance in IPD symptoms. This result indicates that attentional biases play a role in IPD symptoms and seem to occur independently from gender.

The results are consistent with the I-PACE model proposed by Brand et al. (2016), which emphasizes an important role of implicit cognitions in the development and maintenance of Internet-use disorders including IPD. Implicit cognitions are considered as a result of interactions between indicators for sexual arousal and specific predispositions, for example, a high sexual excitability triggered by sexual cues and experiencing gratification while using
Internet pornography. We could show that the subjective sexual arousal due to the presentation of pornographic cues as well as the sexual arousal and the need to masturbate afterward are related to indicators of attentional biases and partially mediates the effect of attentional bias on IPD. Therefore, the results support theoretical assumptions regarding the incentive salience of addiction-related cues and are consistent with studies addressing cue-reactivity and craving in substance-use disorders (Field \& Cox, 2008; Field, Mogg, \& Bradley, 2005; Robbins \& Ehrman, 2004). Specific implicit and affective cognitions, for example, attentional biases, are a direct result of a conditioned response to rewarding cues and are positively reinforced by the experienced gratification. This effect of attentional biases on tendencies toward an IPD could be shown in this study. Similar results were observed for hypersexual individuals, who reacted faster on sexual cues than on neutral compared to healthy individuals (Mechelmans et al., 2014).

We found higher attentional biases in male individuals for the maintained condition and the overall $\mathrm{AB}$ compared to female individuals, but not so for the initial $\mathrm{AB}$. These results are partly contrary to other studies, which could not show any sex differences (Kagerer et al., 2014; Prause, Janssen, \& Hetrick, 2008). This may be explained by the selection of stimuli in this study, as the pornographic pictures used for the Visual Probe Task may have a stronger rewarding character for male than for female individuals and therefore grab stronger attention in male users. Pictures presented in the study by Kagerer et al. (2014) were a combination of stimuli showing hard- and softcore intercourse and were selected previously by a male and female investigator. The procedure was applied to ensure an equally arousing picture set for both sexes. This assumption is supported by sex differences in this study regarding the valence and sexual arousal rating for the pornographic pictures used to induce craving and a higher pornography use by males. Furthermore, male and females showed a different use of Internet-sex-related contents in general. While male users prefer solitary-arousal content in general, such as pornography, female users seek for more

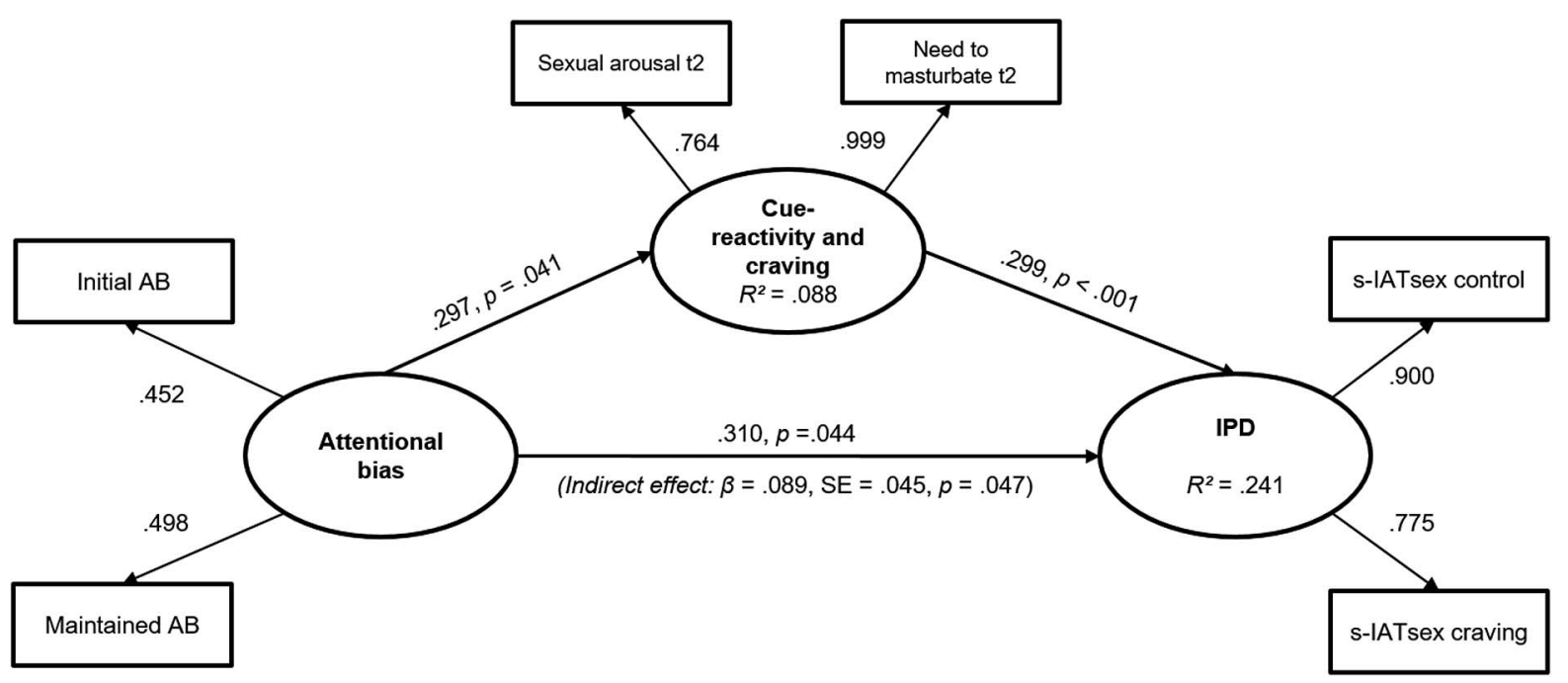

Figure 5. The proposed structural equation model on latent level with IPD symptoms as dependent variable. Direct and indirect effects were found indicating a partial mediation from attentional bias over indicators for cue-reactivity and craving on severity of symptoms of IPD 
interactive applications, such as chatrooms or sex through webcam (Shaughnessy et al., 2011). Therefore, male participants might be strongly attracted by pornographic cues compared to females, potentially as a consequence of conditioning processes.

Regarding the prediction of symptoms of problematic or even pathological use of Internet pornography, participants' sex served as a significant predictor. This result may seem contrary to several studies showing that female users are also prone to get addicted by pornography (Daneback, Ross, \& Månsson, 2006; Green et al., 2012; Laier et al., 2014), even if they prefer more socially interactive applications. Though, prevalence rates in male samples are known to be higher than in female samples (Ross, Månsson, \& Daneback, 2012), as male users use Internet pornography more frequently. Prevalence rates in this sample, although it is not representative, are comparable with other studies with $2.2 \%$ problematic and pathological female users and $8.9 \%$ problematic and pathological male users (based on cut-off scores for the original s-IAT; Pawlikowski et al., 2013).

An enhanced attentional bias toward sexual cues predicted tendencies toward IPD. This effect of implicit cognitions on addictive behaviors is supported by the results from several studies in the field of substance-use disorders (for review, see Field et al., 2014) and behavioral addictions (Mechelmans et al., 2014). However, no interaction of participants' sex and attentional biases on IPD tendencies was found. Obviously, the relationship between IPD symptoms and attention to sexual cues is independent from biological sex, even though males rated pornographic cues as more arousing and more attractive than the female participants. One explanation might be that the visual system is evolutionary programmed to catch attention of cues, which have a biological significance and a reward character for its viewer, such as sexual stimuli (LeDoux, 1996; Rolls, 2000). This more general attentional bias associated with non-drug reward, also referred to as value-driven attention in literature (Anderson, 2016), might also explain small effect sizes of the correlations. Sexual pictures might be associated with both drug- and non-drug rewards and therefore occur also in a non-clinical sample of men and women. However, it has to be noted that the selection of stimuli was not aligned for both sexes, but rather fits male user's preference. Kagerer et al. (2014) argue that females' attention to sexual cues is interfered when they get confronted with same-sex models as found in the study by Schimmack (2005). In terms of tendencies toward IPD, these sexual stimuli also became significant for female individuals. It can be assumed that the anticipated and experienced gratification of Internet pornography positively reinforces the incentive salience of addiction-related cues, whereas, in consequence, the effects of implicit cognitions like attentional biases in Internet pornography-related decision situations might be strengthened independently from sex.

\section{LIMITATIONS AND FURTHER STUDIES}

There are some limitations in this study. We investigated a hypothesis with clinical relevance by conducting a study with a non-clinical sample. Therefore, it remains necessary to address effects of attentional biases on symptoms of IPD with a clinical sample in future studies. Moreover, the selection of sexual stimuli used in the Visual Probe Task needs to be adjusted for female participants and tested in advance to ensure that women's attention is not interfered by any distractors, such as same-sex model intercourse. Moreover, the selection of neutral pictures as cutouts from the pornographic material might not be the most appropriate solution. However, we have created these neutral pictures with respect to comparability in color and color intensity without showing any sex interactions of human bodies. Thus, the orientation and attention on the sexual cues might be increased for the whole sample and not only for individuals showing tendencies toward an IPD. The selection of these cutouts was conducted in order to have the same colors in the pictures, given that it is well known that color of stimuli can also have an effect on attention. Future studies should provide a more distinct control compared to the sexual cues. Furthermore, to address effects of attentional bias in more detail, the Visual Probe paradigm should be extended to measure reaction times on a neutral cue in a pairing of sex and neutral cues compared to reaction times on a neutral cue in a neutral/neutral cue pairing, as it was conducted in the study by Kagerer et al. (2014). This condition would be helpful to understand, if individuals get distracted and slowed down in reaction times by sex cues. Finally, it has to be critically mentioned that pornographic picture presentation was conducted prior to the Visual Probe Task leading to a potential bias on reaction times within the paradigm.

Funding sources: No financial support was received for this study.

Authors' contribution: JS, RS, MB, and JP designed the study. Data collection was carried out by JS and JP. MB, $\mathrm{CL}$, and JP conducted the statistical analysis and interpreted the results. JP wrote the first and final draft of the manuscript. MB supervised the interpretation of the data and writing of the manuscript. All authors contributed to and have approved the final version of the manuscript.

Conflict of interest: The authors declared that no competing interests exist.

\section{REFERENCES}

Anderson, B. A. (2016). What is abnormal about addiction-related attentional biases? Drug and Alcohol Dependence, 167, 8-14. doi:10.1016/j.drugalcdep.2016.08.002

Baron, R. M., \& Kenny, D. A. (1986). The moderator-mediator variable distinction in social psychological research: Conceptual, strategic, and statistical considerations. Journal of Personality and Social Psychology, 51(6), 1173-1182. doi:10. 1037/0022-3514.51.6.1173

Bechara, A. (2005). Decision making, impulse control and loss of willpower to resist drugs: A neurocognitive perspective. Nature Neuroscience, 8(11), 1458-1463. doi:10.1038/nn1584 
Bradley, B. P., Field, M., Healy, H., \& Mogg, K. (2008). Do the affective properties of smoking-related cues influence attentional and approach biases in cigarette smokers? Journal of Psychopharmacology, 22(7), 737-745. doi:10.1177/026988 1107083844

Bradley, B. P., Mogg, K., Wright, T., \& Field, M. (2003). Attentional bias in drug dependence: Vigilance for cigaretterelated cues in smokers. Psychology of Addictive Behaviors, 17(1), 66-72. doi:10.1037/0893-164X.17.1.66

Brand, M., Laier, C., Pawlikowski, M., Schächtle, U., Schöler, T., \& Altstötter-Gleich, C. (2011). Watching pornographic pictures on the Internet: Role of sexual arousal ratings and psychological-psychiatric symptoms for using Internet sex sites excessively. Cyberpsychology, Behavior, and Social Networking, 14(6), 371-377. doi:10.1089/cyber.2010.0222

Brand, M., Young, K. S., Laier, C., Wölfling, K., \& Potenza, M. N. (2016). Integrating psychological and neurobiological considerations regarding the development and maintenance of specific Internet-use disorders: An Interaction of PersonAffect-Cognition-Execution (I-PACE) model. Neuroscience and Biobehavioral Reviews, 71, 252-266. doi:10.1016/j. neubiorev.2016.08.033

Cohen, J. (1992). Statistical power analysis. Current Directions in Psychological Science, 1(3), 98-101. doi:10.1111/1467-8721. ep10768783

Cohen, J., Cohen, P., West, S. G., \& Aiken, L. S. (2003). Applied multiple regression/correlation analysis for the behavioral science (3rd ed.). Mahwah, NJ: Lawrence Erlbaum Associates.

Cooper, A. (1998). Sexuality and the Internet: Surfing into the new millennium. CyberPsychology \& Behavior, 1(2), 187-193. doi:10.1089/cpb.1998.1.187

Daneback, K., Cooper, A., \& Månsson, S.-A. (2005). An Internet study of cybersex participants. Archives of Sexual Behavior, 34(3), 321-328. doi:10.1007/s10508-005-3120-z

Daneback, K., Ross, M. W., \& Månsson, S.-A. (2006). Characteristics and behaviors of sexual compulsives who use the Internet for sexual purposes. Sexual Addiction \& Compulsivity, 13(1), 53-67. doi:10.1080/10720160500529276

Dong, G., Zhou, H., \& Zhao, X. (2011). Male Internet addicts show impaired executive control ability: Evidence from a color-word Stroop task. Neuroscience Letters, 499(2), 114-118. doi:10. 1016/j.neulet.2011.05.047

Döring, N. M. (2009). The Internet's impact on sexuality: A critical review of 15 years of research. Computers in Human Behavior, 25(5), 1089-1101. doi:10.1016/j.chb.2009. 04.003

Drummond, D. C. (2001). Theories of drug craving, ancient and modern. Addiction, 96(1), 33-46. doi:10.1046/j.1360-0443. 2001.961333.x

Ferree, M. (2003). Women and the web: Cybersex activity and implications. Sexual and Relationship Therapy, 18(3), 385-393. doi:10.1080/1468199031000153973

Field, M., \& Cox, W. M. (2008). Attentional bias in addictive behaviors: A review of its development, causes, and consequences. Drug and Alcohol Dependence, 97(1-2), 1-20. doi:10.1016/j.drugalcdep.2008.03.030

Field, M., Marhe, R., \& Franken, I. H. (2014). The clinical relevance of attentional bias in substance use disorders. CNS Spectrums, 19(3), 225-230. doi:10.1017/S10928529 13000321
Field, M., Mogg, K., \& Bradley, B. P. (2005). Craving and cognitive biases for alcohol cues in social drinkers. Alcohol and Alcoholism, 40(6), 504-510. doi:10.1093/alcalc/agh213

Garcia, F. D., \& Thibaut, F. (2010). Sexual addictions. The American Journal of Drug and Alcohol Abuse, 36(5), 254-260. doi:10.3109/00952990.2010.503823

Georgiadis, J. R., \& Kringelbach, M. L. (2012). The human sexual response cycle: Brain imaging evidence linking sex to other pleasures. Progress in Neurobiology, 98(1), 49-81. doi:10. 1016/j.pneurobio.2012.05.004

Green, B., Carnes, S., Carnes, P. J., \& Weinmann, E. A. (2012). Cybersex addiction patterns in a clinical sample of homosexual, heterosexual, and bisexual men and women. Sexual Addiction \& Compulsivity, 19(1-2), 77-98. doi:10.1080/ 10720162.2012.658343

Griffiths, M. D. (2001). Sex on the Internet: Observations and implications for Internet sex addiction. Journal of Sex Research, 38(4), 333-342. doi:10.1080/00224490109552104

Griffiths, M. D. (2012). Internet sex addiction: A review of empirical research. Addiction Research \& Theory, 20(2), 111-124. doi:10.3109/16066359.2011.588351

Grov, C., Gillespie, B. J., Royce, T., \& Lever, J. (2011). Perceived consequences of casual online sexual activities on heterosexual relationships: A U. S. online survey. Archives of Sexual Behavior, 40(2), 429-439. doi:10.1007/s10508-010-9598-Z

Hald, G. M., \& Malamuth, N. M. (2008). Self-perceived effects of pornography consumption. Archives of Sexual Behavior, 37(4), 614-625. doi:10.1007/s10508-007-9212-1

Hoffmann, H., Janssen, E., \& Turner, S. (2004). Classical conditioning of sexual arousal in women and men: Effects of varying awareness and biological relevance of the conditioned stimulus. Archives of Sexual Behavior, 33(1), 43-53. doi:10.1023/B: ASEB.0000007461.59019.d3

Hu, L., \& Bentler, P. M. (1995). Evaluating model fit. In R. H. Hoyle (Ed.), Structural equation modeling concepts issues and applications (pp. 76-99). London, UK: Sage Publications.

Hu, L., \& Bentler, P. M. (1999). Cutoff criteria for fit indexes in covariance structure analysis: Conventional criteria versus new alternatives. Structural Equation Modeling: A Multidisciplinary Journal, 6(1), 1-55. doi:10.1080/10705519909540118

Jeromin, F., Nyenhuis, N., \& Barke, A. (2016). Attentional bias in excessive Internet gamers: Experimental investigations using an addiction Stroop and a Visual Probe. Journal of Behavioral Addictions, 5(1), 32-40. doi:10.1556/2006.5.2016.012

Kagerer, S., Wehrum, S., Klucken, T., Walter, B., Vaitl, D., \& Stark, R. (2014). Sex attracts: Investigating individual differences in attentional bias to sexual stimuli. PLoS One, 9(9), e107795. doi:10.1371/journal.pone.0107795

Klucken, T., Schweckendiek, J., Merz, C. J., Tabbert, K., Walter, B., Kagerer, S., Vaitl, D., \& Stark, R. (2009). Neural activations of the acquisition of conditioned sexual arousal: Effects of contingency awareness and sex. The Journal of Sexual Medicine, 6(11), 3071-3085. doi:10.1111/j.1743-6109.2009.01405.x

Kuss, D. J., Griffiths, M. D., Karila, L., \& Billieux, J. (2014). Internet addiction: A systematic review of epidemiological research for the last decade. Current Pharmaceutical Design, 20(25), 4026-4052. doi:10.2174/13816128113199990617

Laier, C., \& Brand, M. (2014). Empirical evidence and theoretical considerations on factors contributing to cybersex addiction from a cognitive-behavioral view. Sexual Addiction \& 
Compulsivity, 21(4), 305-321. doi:10.1080/10720162.2014. 970722

Laier, C., Pawlikowski, M., Pekal, J., Schulte, F. P., \& Brand, M. (2013). Cybersex addiction: Experienced sexual arousal when watching pornography and not real-life sexual contacts makes the difference. Journal of Behavioral Addictions, 2(2), 100-107. doi:10.1556/JBA.2.2013.002

Laier, C., Pekal, J., \& Brand, M. (2014). Cybersex addiction in heterosexual female users of Internet pornography can be explained by gratification hypothesis. Cyberpsychology, Behavior and Social Networking, 17(8), 505-511. doi:10.1089/ cyber.2013.0396

Laier, C., Pekal, J., \& Brand, M. (2015). Sexual excitability and dysfunctional coping determine cybersex addiction in homosexual males. Cyberpsychology, Behavior, and Social Networking, 18(10), 575-580. doi:10.1089/cyber.2015.0152

LeDoux, J. E. (1996). The emotional brain. The mysterious underpinnings of emotional life. New York, NY: Simon \& Schuster.

Lorenz, R. C., Krüger, J.-K., Neumann, B., Schott, B. H., Kaufmann, C., Heinz, A., \& Wüstenberg, T. (2012). Cue reactivity and its inhibition in pathological computer game players. Addiction Biology, 18(1), 134-146. doi:10.1111/ j.1369-1600.2012.00491.x

Mechelmans, D. J., Irvine, M., Banca, P., Porter, L., Mitchell, S., Mole, T. B., Lapa, T. R., Harrison, N. A., Potenza, M. N., \& Voon, V. (2014). Enhanced attentional bias towards sexually explicit cues in individuals with and without compulsive sexual behaviours. PLoS One, 9(8), e105476. doi:10.1371/journal. pone. 0105476

Meerkerk, G.-J., van den Eijnden, R., \& Garretsen, H. (2006). Predicting compulsive Internet use: It's all about sex! CyberPsychology \& Behavior, 9(1), 95-103. doi:10.1089/cpb. 2006.9.95

Metcalf, O., \& Pammer, K. (2011). Attentional bias in excessive massively multiplayer online role-playing gamers using a modified Stroop task. Computers in Human Behavior, 27(5), 1942-1947. doi:10.1016/j.chb.2011.05.001

Muthén, L. K., \& Muthén, B. O. (2011). Mplus. Los Angeles, CA: Muthén \& Muthén.

Paul, B. (2009). Predicting Internet pornography use and arousal: The role of individual difference variables. Journal of Sex Research, 46(4), 344-357. doi:10.1080/00224490902754152

Pawlikowski, M., Altstötter-Gleich, C., \& Brand, M. (2013). Validation and psychometric properties of a short version of Young's Internet Addiction Test. Computers in Human Behavior, 29(3), 1212-1223. doi:10.1016/j.chb.2012.10.014

Prause, N., Janssen, E., \& Hetrick, W. P. (2008). Attention and emotional responses to sexual stimuli and their relationship to sexual desire. Archives of Sexual Behavior, 37(6), 934-949. doi:10.1007/s10508-007-9236-6

Robbins, S. J., \& Ehrman, R. N. (2004). The role of attentional bias in substance abuse. Behavioral and Cognitive Neuroscience Reviews, 3(4), 243-260. doi:10.1177/1534582305275423
Robinson, T. E., \& Berridge, K. C. (1993). The neural basis of drug craving: An incentive-sensitization theory of addiction. Brain Research Reviews, 18(3), 247-291. doi:10.1016/0165-0173 (93)90013-P

Robinson, T. E., \& Berridge, K. C. (2000). The psychology and neurobiology of addiction: An incentive-sensitization view. Addiction, 95(8s2), 91-117. doi:10.1046/j.1360-0443.95. 8s2.19.x

Robinson, T. E., \& Berridge, K. C. (2001). Incentive-sensitization and addiction. Addiction, 96(1), 103-114. doi:10.1046/j.13600443.2001.9611038.x

Robinson, T. E., \& Berridge, K. C. (2008). The incentive sensitization theory of addiction: Some current issues. Philosophical Transactions of the Royal Society B: Biological Sciences, 363(1507), 3137-3146. doi:10.1098/rstb.2008.0093

Rolls, E. T. (2000). The orbitofrontal cortex and reward. Cerebral Cortex, 10(3), 284-294. doi:10.1093/cercor/10.3.284

Ross, M. W., Månsson, S.-A., \& Daneback, K. (2012). Prevalence, severity, and correlates of problematic sexual Internet use in Swedish men and women. Archives of Sexual Behavior, 41(2), 459-466. doi:10.1007/s10508-011-9762-0

Sayette, M. A., Shiffman, S., Tiffany, S. T., Niaura, R. S., Martin, C. S., \& Shadel, W. G. (2000). The measurement of drug craving. Addiction, 95(8s2), 189-210. doi:10.1046/j.13600443.95.8s2.8.x

Schimmack, U. (2005). Attentional interference effects of emotional pictures: Threat, negativity, or arousal? Emotion, 5(1), 55-66. doi:10.1037/1528-3542.5.1.55

Shaughnessy, K., Byers, E. S., Clowater, S. L., \& Kalinowski, A. (2014). Self-appraisals of arousal-oriented online sexual activities in university and community samples. Archives of Sexual Behavior, 43(6), 1187-1197. doi:10.1007/s10508013-0115-z

Shaughnessy, K., Byers, E. S., \& Walsh, L. (2011). Online sexual activity experience of heterosexual students: Gender similarities and differences. Archives of Sexual Behavior, 40(2), 419-427. doi:10.1007/s10508-010-9629-9

Snagowski, J., Laier, C., Duka, T., \& Brand, M. (2016). Subjective craving for pornography and associative learning predict tendencies towards cybersex addiction in a sample of regular cybersex users. Sexual Addiction \& Compulsivity, 23(4), 342-360. doi:10.1080/10720162.2016.1151390

van Hemel-Ruiter, M. E., de Jong, P. J., Ostafin, B. D., \& Wiers, R. W. (2015). Reward sensitivity, attentional bias, and executive control in early adolescent alcohol use. Addictive Behaviors, 40, 84-90. doi:10.1016/j.addbeh.2014.09.004

Young, K. S. (1998). Internet addiction: The emerge of a new clinical disorder. CyberPsychology \& Behavior, 1(3), 237-244. doi:10.1089/cpb.1998.1.237

Young, K. S., Pistner, M., O’Mara, J., \& Buchanan, J. (1999). Cyber disorders: The mental health concern for the new millennium. CyberPsychology \& Behavior, 2(5), 475-479. doi:10.1089/cpb.1999.2.475 